\title{
Bladder invasive transitional cell carsinoma, which improves from cystitis cystica and glandularis; is cystitis cystica and glandularis a precancerous lesion?
}

\section{Sistitis sistika ve glandularisi takiben gelişen mesane invaziv değişici hücreli karsinomu; sistitis sistika ve glandularis prekanseröz bir lezyon mudur?}

\author{
Eşref Oğuz Güven ${ }^{1}$, İsmail Selvi ${ }^{1}$, Erdem Öztürk ${ }^{1}$, Erman Damar $^{1}$, Füsun Ardıç Yükrük² ${ }^{2}$ Fatih Hızlı ${ }^{1}$, Halil \\ Başar $^{1}$ \\ ${ }^{1}$ Abdurrahman Yurtaslan Onkoloji Eğitim Ve Araştırma Hastanesi, Üroloji Kliniği, Ankara, Türkiye \\ ${ }^{2}$ Abdurrahman Yurtaslan Onkoloji Eğitim Ve Araştırma Hastanesi, Patoloji Kliniği, Ankara, Türkiye
}

Dergiye Ulaşma Tarihi: 19.02.2016 Dergiye Kabul Tarihi: 12.03.2017 Doi: 10.5505/aot.2017.81300

\section{ÖZET}

Sistitis sistika ve glandularis, mesane epitelyumunun kronik inflamasyon veya obstruksiyonuna sekonder olarak oluşan benign proliferatif bir lezyonudur. Sıklıkla asemptomatik olarak seyretmekle beraber nadiren rekürren gross hematüri, irritatif veya obstruktif üriner semptomlara da yol açabilmektedir. İntestinal metaplazi ve mesane karsinomu ile ilişkisi, prekanseröz bir lezyon olup olmadığı halen tartışmalı olmakla beraber, pek çok araştırmada mesanede karsinom ile eş zamanlı birlikteliği tespit edilmiştir. Bu vakada daha önceden T1 evre mesane ürotelyel karsinomu olduğu bilinen bir hastada, takip eden süre içerisinde sistitis sistika ve glandularis gelişen ve bunun zemininde kas invaze mesane ürotelyum karsinomu oluşan bir olgu sunulmuştur. Her ne kadar literatürde, kısa dönemli takiplerde karsinoma progresyon gösterdiğine dair kanıtlar olmasa da bu olguda 3 ay gibi kısa bir dönemde karsinom gelişmiş, ancak bunun bir progresyon mu yoksa senkron bir birliktelik mi olduğu kesin olarak bilinmemektedir.

Anahtar Kelimeler: Mesane prekanseröz lezyon, sistitis glandularis, sistitis sistika

\begin{abstract}
Sistitis cystica and glandularis are benign proliferative lesions secondary to chronic inflammation or obstruction of bladder epithelium. It is often asymptomatic, but rarely can lead to recurrent gross hematuria, irritative or obstructive urinary symptoms. Concurrent with intestinal metaplasia and bladder carcinoma, whether it is a precancerous lesion or not, is controversial, and in many studies concurrent presence of carcinoma in bladder has been detected. In this case, we present a patient with T1 stage urothelial carcinoma of the bladder who developed cystitis and glandularis within the following period and progression to muscle invasive bladder urothelial carcinoma. Although there is no evidence in the literature that it progresses to carcinoma in short-term followup, in this case carcinoma develops as short as 3 months, but it is unclear whether it has a progression or a synchronous association.
\end{abstract}

Keywords: Bladder precancerous lesion, cystitis cystica, cystitis glandularis

\section{Giriş}

Otopsi çalışmalarında prevelansının \%60 olduğu saptanmış olan sistitis sistika, Von Brunn adalarının kistik dilatasyonuyla ile karakterize, benign karakterli ürotelyal bir lezyondur. $\mathrm{Bu}$ adalar çoğunlukla glandüler yapılar içerdiğinden, bu durumda sistitis glandularis olarak adlandırılmaktadır. Sistitis sistika, sistitis glandularis ve von brunn adas1 hiperplazisi genellikle birlikte bulunur ve her yaşta görülebilirler (1).
Sistitis glandularis (CG), mesane transizyonel hücrelerinin glanduler metaplaziye gitmesi ile karakterize nadir görülen bir proliferatif mesane hastalığıdır. Sistitis Sistica et Glandularis (CCEG) ilk kez Morgagni tarafindan 1761'de tanımlanmıştır (2). 1950'de Immergut ve Cottler yaptıkları bir çalışmada, mesane adenokarsinomu gelişiminde CCEG'in etkili olabileceği yönünde görüş bildirmişlerdir (3). O tarihten sonra yapılan çeşitli çalışmalarda, CCEG bir adenokarsinom prekürsörü olarak ileri sürülmüştür (4). İntestinal tip CG ve diffüz lezyonlar premalign olarak tanımlansa da, bazı 
çalışmalara göre CCEG, klinik olarak önemsiz, kronik ve sessiz

bir histolojik lezyondur. Smith ve ark.' na göre CCEG, malignite için artmış bir risk faktörü değildir (5).

\section{Olgu}

73 yaşında bir erkek hastaya diş merkezde 2009 yılında mesane tümörü tanısıyla transüretral rezeksiyon (TUR-M) yapılmış ve patoloji sonucu T1G3 gelmesi üzerine 6 kür intrakaviter BCG tedavisi uygulanmıştır. Ekim 2012'de sağ yan ağrıs1 ve hematüri nedeniyle yapılan incelemelerde, kontrastsiz bilgisayarlı tomografide (BT) sağ üreter alt kesimde parsiyel obstruksiyon yaratan $11 \mathrm{~mm}$ çapında taş saptanmıştır. Sağ üretere üreterorenoskopi (URS) yapılan hastada üst üriner sistemden sitoloji de alınmış, sonucu normal gelmiştir.

Ocak 2014'te infravezikal obstruksiyon nedeniyle prostat dokusuna TUR yapılmış, patoloji sonucu benign adenomatöz hiperplazi şeklinde yorumlanmıştır. Nisan 2014'te hematüri nedeniyle yapılan sistoskopide mesane kubbesinde adenokarsinomu düşündürecek görüntüde şüpheli lezyonlar olması üzerine TUR-M yapılmış, patoloji sonucu sistitis sistika-glandularis olarak gelmiştir (Resim 1). Şubat 2015'teki kontrol ultrasonografide (USG) mesane içinde patolojik oluşum saptanmamıştır. Mayıs 2015'te hematüri olması üzerine yapılan sistoskopide şüpheli vejetatif lezyonlar gözlenmesi üzerine yapılan TUR-M patolojisi kas invaze low grade ürotelyal karsinom şeklinde gelmiştir. Hastanın özgeçmişinde sigara kullanımı olmayıp diabetes mellitus ve koroner arter hastalığ mevcuttur.

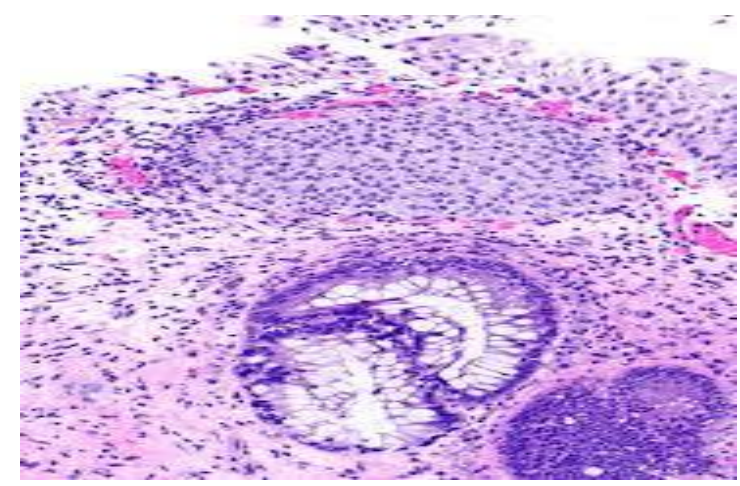

Resim 1: TUR-M patolojisine göre sistitis sistika - sistitis glandularis bulgusunu kuvvetlendiren glanduler alanları

\section{Tartışma}

Sistitis glandularis, üriner mesane epitelinin mukoza ve submukozasının içindeki mukus üreten glandların nadir görülen bir metaplazik proliferatif hastalığıdır. Kronik inflamasyon varlığında mesane ürotelyumda hiperproliferasyon başlar, ürotelyal nest yapıları lamina propria içerisinde görünür hale gelir, kistik ve glanduler lezyonlara diferansiyasyon başlar. Mikroskopik bir bulgu olmasına rağmen nadiren büyük görünür makroskopik boyutlara ulaşabilmektedir. $\mathrm{Bu}$ lezyonların mesane adenokarsinomuna progresyonu halen şüphelidir. Benzer şekilde bunlara erken agresif tedavi yaklaşımları da tartışmalıdır. Görünür bir lezyon yokluğunda, tedavi irritatif faktörlerin eradikasyonuna dayanan medikal yaklaşımlardır. Cerrahi yaklaşım, rekürren hematüri varlığı, mesane çıkım obstruksiyonu yaratan psödoneoplastik bir lezyon oluşumu varsa önerilmektedir. Çeşitli çalışmalar transüretral rezeksiyonu ve adenokarsinomatöz değişiklikler saptanana kadar sistoskopik takibi önermektedir. Bazıları ise agresif tedavileri savunmaktadir.

Etyolojide mesanenin kronik irritasyonuna yol açabilecek tekrarlayan kateterizasyonlar, taş,kronik inflamasyon kadar, mesane ekstrofisi, nörojenik mesane, pelvik lipomatozis de ilişkili tutulmaktadır. Ayrica avitaminosis, alerji,hormonal imbalans, karsinojenik ilaçlar, Ig A ilişkili immün mekanizmaların da rol oynayabileceği söylenmektedir (6).

CG olgular1 genellikle asemptomatik seyretmektedir. Semptomatik hastalarda ise genellikle başvuru yakınması gross hematüri, kronik sistit ve irritatif işeme semptomlarıdır. Çok büyük boyutlara ulaştığında ise obstruktif üriner semptomlar verebilmekte, hatta mesane boynu ve trigonda lokalize olursa hidronefroza da yol açabilmektedir. Hatta bazen CG lezyonlarının mesanede nöroanatomik değişiklikler yaratarak üst üriner traktı da etkileyebileceği bildirilmiştir.

Yuksel ve ark.'nın çalışmasında, CG tanısı almış ancak ilerleyen dönemde çeşitli merkezlerde transüretral rezeksiyon, parsiyel sistektomi, intravezikal mitomisin ve BCG uygulamaları yapılmasına rağmen bu modalitelere dirençli hale gelmiş ve ciddi makroskopik hematüri, irritatif üriner

Adress for correspondence: Uzm. Dr. Erdem Öztürk, Ankara Dr. Abdurrahman Yurtarslan Onkoloji Eğitim Ve Araştırma Hastanesi Yenimahalle Ankara - Türkiye 
semptomları olan bir hastada 6 ay boyunca oral steroid tedavisi (ilk 3 ay $10 \mathrm{mg} /$ gün oral prednizolon, semptomlar için ayrıca propiverin hidroklorür ve profilaktik antibiyotik; son 3 ay ise $5 \mathrm{mg} /$ gün oral prednizolon) dramatik bir iyileşme yaratmıştır (7).

Histolojik olarak incelendiğinde, CG lezyonları lamina propriadaki glandların proliferasyonundan oluşur. Glandlar goblet hücresi içeren kolumnar epitelyum tarafindan çevrilmiştir. Musin üretimi ve stroma içerisine fokal musin ekstravazasyonu tanımlanmıştır. Belirgin nükleer hiperkromazi, pleomorfizm, psödostratifikasyon yoktur. Glandların etrafinda akut veya kronik inflamasyonla uyumlu yapısal değişiklikler mevcuttur (1).

İntestinal tip $\mathrm{CG}(\mathrm{CGIT})$ ayıric1 tanısinda, adenokarsinom, endoservikosis ve nefrojenik adenom yer almaktadır (8). İntestinal tip CG'da adenokarsinomdan farklı olarak, atipik epitelyal hücreler, desmoplazi, detrusor kas invazyonu yoktur. Nükleer mitoz, fokal detrusor invazyonu nadiren gözlenir, fakat bu bulguların derecesi de adenokarsinomda görülenden çok daha azdır.

Endoservikosis, baskın olarak endoservikal tip epitelyum ile karakterize glanduler bir mesane lezyonudur. Genellikle reproduktif dönemdeki kadınlarda gözlenmektedir. Endoservikosis detrusör kas yapısı içermekteyken, CGIT hemen her zaman lamina propria ile sinırlıdır.

Nefrojenik adenom ise, manipulasyon yapılmış veya travmatize mesanelerde gözlenen, çoğunlukla yetişkinlerde olan bir başka lezyondur. Siklıkla kronik sistit ile ilişkilidir. CCEG'den farklı olarak transizyonel epitelyum ile çevrili değildir.

CCEG'in klinik açıdan doğal seyri halen net değildir. Shaw ve ark. 1958'de ilk kez kronik üriner sistem enfeksiyonu olan bir hastada saptanan CCEG'in adenokarsinoma progresyonunu tarifledi (9). Susmano ve ark. da sonraki yıllarda CCEG'den adenokarsinoma dönüşüm yapan iki olgu açıkladı (10). 1980'de ilk kez, CCEG ve pelvik lipomatozis olan bir hastada mesane adenokarsinom gelişimi açıklandı (11). Bunu takip eden çok sayıda çalışmada CCEG bir premalign lezyon olarak görüldügünden, yıllık sistoskopik takip ve random mesane biyopsisi önerilmeye başlandı (12).

Buna karşılık, Ito ve ark. 'nın yaptığ 125 olguluk bir otopsi serisinde sağlıklı mesanelerin \%40-92'sinde histolojik olarak CG varlığ 1 saptandı (13). Bu nedenle intestinal metaplaziyi mesane kanseri için bir faktörü olarak değerlendirmemektedirler. Literatürde sistitis glandularisin bir premalign lezyon olarak gösterildiği 16 olgu vardır $(11,12)$. Bu 16 olgunun 10'unda CG ve senkron adenokarsinom birlikteliği mevcut olduğundan, Smith ve ark.'na göre, bunun bir risk faktörü olarak gösterilmesinin ne derece doğru olduğu tartışmalıdır (5).

Y1 ve ark.'nın, 1994 ile 2010 yılları arasında takip ettikleri, 155 tipik CG, 11 intestinal tip CG tanıs1 alan toplam 166 hastanın 15'inde (\%9) eş zamanlı mesane karsinomu mevcuttur. Ancak takip boyunca her iki CG alt grubunda da yeni bir karsinom geliştiği saptanmamıştır. Bu da kısa dönemde sistitis glandularisin malignite için artmış bir risk faktörü olmadığını, kısa periyotlarla tekrar kontrol sistoskopi yapılmasinın gereksiz olduğunu, ancak kısa bir takip uygulandığ için,uzun dönem sonuçları hakkında tahmin yapılamayacağını bildirmiştir (14).

İntestinal metaplazi (IM), tek başına veya CCEG ile ilişkili olarak saptanmaktadır. Mikroskopik olarak, goblet hücre varlığ1 mevcut olup morfolojik olarak kolonik mukozayı andıran bir görünüme sahiptir. Mesanede IM varlığında, CDX2 ve CK20 ile immünoreaktif olarak pozitif sonuç vermektedir. Bu markırlar CCEG'de ise sıklıkla negatiftir. CCEG ile ilişkili olan IM bazı araştırmacılar tarafından "intestinal tip CG" olarak da isimlendirilmektedir. CCEG siklıkla benign, reaktif bir durum olsa da, pelvik lipomatosis ve mesane adenokarsinomu ile ilişkilendiren çalışmalar da mevcuttur (12). Çin'de yapılan son çalışmaların birinde, CG tanis1 olan hastalarda \%21'lik bir oran ile maligniyete progresyon izlenmiştir (14). Sağlıklı hayvan modellerinde yapılan başka bir çalışmada ise üretelyumda proliferatif değişikliklerin yaygın olduğu, ancak bunların hiçbir neoplastik değişiklikle ilişkili olmadığı gösterilmiştir (12).

Smith ve ark. 'nın yaptığ 136 hastayı içeren çalışmada, CCEG ve IM olan gruplarda benzer oranlarda (\%33'e karş1 \%37) tesadüfi karsinom tanımlanmıştır. Ancak bunlar ile mesane karsinomu gelişimi arasında etyolojik açıdan bir ilişki net olarak kurulamamıştır. Tek bir olguda, önceki biyopsi bulguları CCEG olan hastada üretelyal kanser gelişmiştir, ancak bu 
hastada daha önce üst üriner trakt kanseri (ÜÜTK) nedeniyle parsiyel nefrektomi öyküsü de bulunmaktaydı. Ve ÜÜTK tanısı ile mesane kanseri tanısı arasında 3 aylık bir süre mevcuttu. $\mathrm{Bu}$ bulgu da CCEG'nin bir prekürsör gibi davranmasından ziyade, mevcut ÜÜTK'ne bağlı mesanede bir de novo karsinom geliştiği savını güçlendirmektedir (5).

Pelvik lipomatozis (PL) tanısı seyrektir ve kitlenin diştan bası ile mesane boynunda obstruksiyon oluşturduğu, kronik üriner staza yol açtığ 1 , buna bağlı olarak da mesanede proliferatif değişiklikler oluşturduğu ve bunların radyolojik olarak tanımlanabileceği görüşü ön plandadır. Bazı vaka serilerinde, PL ile CCEG arasında \%75 oranında bir ilişki gösterilmiştir (15). Ancak Smith ve ark.'nın çalışmasında, bu ilişki ortaya konulamamıştır. İntravenöz pyelografi (IVP), BT, magnetik rezonans (MR) gibi abdominal görüntülemelerde mesane şekil anomalileri, aşırı pelvik yă depozisyonu bulguları saptanamamıştır (5).

Smith ve ark. sadece 23 hastada (\%33) uzun dönem sistoskopik değerlendirme ve sitoloji çalışıldığ 1 , bunların ise hiçbirinde yeni bir mesane karsinomu saptanmadığını

Conflict of interest: None

\section{Referanslar}

1. Wiener DP, Koss LG, Sablay B, Freed SZ. The prevalence and significance of Brunn's nests, cystitis cystica and squamous metaplasia in normal bladders. J Urol. 1979;122(3):317-21.

2. Morgagni G and Alexander B. The Seats and Causes of Diseases Investigated by Anatomy. Vol 3. 2nd edition. London, A. Millar; and T. Cadell, his successor and Johnson and Payne, London, pp 835, 1769.

3. Immergut S, Cottler ZR. Mucin producing adenocarcinoma of the bladder associated with cystitis follicularis and glan-dularis. Urol Cutaneous 1950;54:531-34

4. Nesbit RM: Is cystitis cystica an innocent or a malefic lesion? J Urol 1956;75:443-47

5. Smith AK, Hansel DE and Jones JS: Role of cystitis cystica et glandularis and intestinal metaplasia in development of bladder carcinoma. Urology 2008;71:915-18

6. Capozza N, Collura G, Nappo S, et al. Cystitis glandularis in children. BJU Int 2005;95:411-3.

7. Yuksel OH, Urkmez A, Erdogru T,et al. The role of steroid treatment in intractable cystitis belirtmekle beraber çalışmalarının retrospektif oluşu,az sayıda hasta grubunda yapılmış olması ve nispeten kısa takip süreleri nedeniyle konu üzerinde daha fazla sayıda ve prospektif çalışmalar yapılması gerektiği inancındadırlar (5).

\section{Sonuç}

CCEG ve IM olguları, sıklıkla mesane karsinomu ile eş zamanlı tesadüfi olarak saptanabilmektedir. Her ne kadar bugüne kadar yapılan uzun dönem takiplerde bu lezyonlar preneoplastik olarak desteklenemese de daha uzun takip süreli, daha geniş hasta gruplarında, prospektif olarak çalışılmaya büyük ihtiyaç vardır. Aralarında mesane karsinomuna gidişi ciddi oranda etkileyen bir ilişki saptanması halinde, bu durum CCEG veya intestinal tip CG tanıs1 alan hastalarda ilk andan itibaren daha yakın sistoskopik gözlemler ve sitolojik incelemelerle mesane karsinomuna gidişi kontrol altına alabilecek ve hastanın genel sağ kalımına ve hastalıksız sağ kalımına dramatik düzeyde katk1 sağlayabilecektir.

Çıkar Çatışması: Yok glandularis: A case report and literature review. Can Urol Assoc J 2015;9:5-6

8. Young RH, Bostwick DG. Florid cystitis glandularis of intestinal type with mucin extravasation: a mimic of adenocarcinoma. Am J Surg Pathol 1996;20:1462-68

9. Shaw JL, Gislason GJ,Imbriglia JE Transition of cystitis glandularis to primary adenocarcinoma of the bladder. J Urol 1958;79:815-22

10. Susmano D, Rubenstein AB, Dakin AR, Lloyd FA. Cystitis glandularis and adenocarcinoma of the bladder. Urology 1971;105:671-74

11. O'Brien AM,Urbanski SJ. Papillary adenocarcinoma in situ of bladder. J Urol 1985;134:544-46

12. Gordon NS, Sinclair RA, Snow RM. Pelvic lipomatosis with cystitis cystica, cystitis glandularis and adenocarcinoma of the bladder: first reported case. Aust NZ J Surg 1990;60:22932

13. Ito N, Hirose M, Shirai T, Tsuda H, Nakanishi K,Fukushima S. Lesions of the urinary bladder 
epithelium in 125 autopsy cases. Acta Pathol Jpn 1981;31:545-57

14. Y1 X, Lu H, Wu Y et al. Cystitis glandularis: A controversial premalignant lesion. Oncology Letters 2014;8:1662-64
15. Klein FA, Smith MJ, Kasenetz I. Pelvic lipomatosis: 35-year experience. J Urol 1988;139:998-1001 